\title{
Influência do Orvalho e Volume de Calda de Aplicação na Eficácia do GlyPhosate na Dessecação de Brachiaria plantaginea ${ }^{1}$
}

\author{
Influence of Dew and Spray Volume on the Efficacy of Glyphosate for Brachiaria plantaginea \\ Burndown
}

ROMAN, E.S. ${ }^{2}$, VARGAS, L. ${ }^{2}$, RIBEIRO, M.C.F. ${ }^{4}$ LUIZ, A.R.M. ${ }^{5}$

\begin{abstract}
RESUMO - A eficácia de herbicidas é influenciada por diversos fatores que afetam a absorção e a translocação desses compostos na planta. A absorção de herbicidas pelas plantas, por exemplo, é influenciada, tanto física como biologicamente, pela temperatura e pela umidade relativa do ar dentro do dossel. Com a diminuição da umidade relativa do ar e/ou com o aumento da temperatura, as gotas da pulverização secam mais rapidamente e a absorção do produto diminui, ou até mesmo cessa, afetando o desempenho biológico. Com base nessa premissa, o presente estudo teve como objetivo examinar a influência do orvalho e do volume de calda de aplicação na eficiência de doses de glyphosate para o controle de Brachiaria plantaginea. Foram observadas interações significativas entre volume de calda, orvalho e dose de glyphosate. O volume mais baixo (100 $\left.\mathrm{L} \mathrm{ha}^{-1}\right)$ resultou em melhor controle da espécie, especialmente quando o herbicida foi usado na menor dose $\left(90 \mathrm{~g} \mathrm{ha}^{-1}\right)$. A presença de orvalho nas folhas causou reduções na atividade do produto, especialmente quando aplicado na menor dose e combinado com maior volume de calda.
\end{abstract}

Palavras-chave: herbicidas, absorção, concentração e diluição.

\begin{abstract}
The efficacy of herbicides is influenced by several factors affecting the absorption and translocation of these compounds in the plant. Herbicide plant absorption, for example, is both physically and biologically influenced by temperature and air relative humidity in the plant canopy. With the reduction in relative air humidity and/or increase in temperature, the spray droplets dry more rapidly and the absorption of the herbicide decreases or even stops, affecting the biological performance. Based on that, this research aimed to study the influence of dew and spray volume on the efficacy of glyphosate rates in the control of $\boldsymbol{B}$. plantaginea. There were significant interactions among volume of water, dew and rate of glyphosate. The lower the water volume, the more effective the glyphosate activity was, especially when applied at the lowest tested rate $\left(90 \mathrm{~g} \mathrm{ha}^{-1}\right)$. The presence of dew on the leaves caused reductions in the activity of the product, mainly when the lowest rate was combined with the highest water volume.
\end{abstract}

Key words: herbicides, absorption, rates and water volume.

Recebido para publicação em 9.2.2003 e na forma revisada em 10.9.2004.

2 Eng.-Agr., Ph.D, Pesquisador da Embrapa Trigo, Caixa Postal 451, 99001-970 Passo Fundo-RS, <eroman@ cnpt.embrapa.br>. ${ }^{3}$ Eng.-Agr., D.S., Pesquisador do Centro Nacional de Pesquisa Uva e Vinho, Vacaria-RS. ${ }^{4}$ Acadêmico do curso de Agronomia da Universidade de Passo Fundo, Caixa Postal 451, 99001-970 Passo Fundo-RS. ${ }^{5}$ Estudante do Curso de Mestrado em Produção Vegetal da Universidade de Passo Fundo. 


\section{INTRODUÇÃO}

A eficiência de herbicidas é influenciada por diversos fatores, que afetam a absorção e a translocação desses compostos na planta. A absorção, por exemplo, é influenciada, tanto física como biologicamente, pela temperatura e pela umidade relativa do ar no dossel. Com a diminuição da umidade relativa do ar e/ou com o aumento da temperatura, as gotas da pulverização secam mais rapidamente. Em termos fisiológicos, a umidade relativa afeta o status hídrico da planta e, assim, a abertura estomática e a permeabilidade cuticular (Hammerton, 1967). A absorção desses compostos diminui, ou até mesmo cessa, afetando o desempenho biológico.

Além disso, temperaturas acima da temperatura ótima causam fechamento de estômatos, reduzindo a absorção de herbicidas (Ritter \& Coble, 1981).

Umidade relativa baixa e elevada temperatura do ar favorecem a volatilização de produtos, possibilitando sua deriva, pela ação de ventos que os carregam, na forma de vapor, para longe do alvo.

A ausência de ventos fortes nas primeiras horas da manhã e a ocorrência de temperatura amena e de umidade relativa do ar elevada reduzem as possibilidades de deriva e de perdas por evaporação, aumentando a eficiência do produto. No entanto, a ocorrência de orvalho faz com que ocorram atrasos nas aplicações de herbicidas em pós-emergência. Especulase que seria melhor esperar a redução do excesso de umidade sobre a folhagem para que sejam realizadas as pulverizações e, assim, evitar possíveis perdas de produto por escorrimento da calda. Por outro lado, o orvalho pode melhorar a eficiência de herbicidas através da redistribuição do produto na planta, bem como possibilitar a redução do volume de calda de pulverização e aumentar a autonomia do pulverizador. Os custos de aplicação seriam, assim, reduzidos pelo menor tempo de operação do uso de equipamentos, com conseqüente economia de combustivel e de mão-de-obra.

A temperatura e a umidade relativa do ar são as variáveis ambientais que mais têm sido estudadas com respeito aos seus efeitos sobre a eficiência de herbicidas. No entanto, não há informações disponíveis sobre os efeitos da presença de orvalho, e de suas interações com o volume de calda e as doses de herbicidas, no controle de plantas daninhas.

A formação de orvalho depende da temperatura e da umidade relativa do ar, de forma que, quanto maior a temperatura, maior a quantidade de vapor de água que o ar pode reter. O ponto de orvalho é a temperatura na qual a quantidade de vapor de água existente no ar atinge o nivel de saturação. Quando a temperatura cai abaixo do ponto de orvalho, começa a condensação do vapor de água contido no ar, formando o orvalho.

A eficiência de herbicidas no controle de plantas daninhas também depende da quantidade de água usada como veículo em sua aplicação. A eficiência de glyphosate aumenta quando diminui o volume reduzido de calda de pulverização. Essa melhor eficiência tem sido atribuída à melhor cobertura da folhagem (Ambach \& Ashford, 1982) e à maior concentração de ingrediente ativo nas gotículas da pulverização (Jordan, 1981).

\section{MATERIAL E MÉTODOS}

O objetivo do presente trabalho foi examinar a influência do orvalho e do volume de calda de aplicação sobre a eficiência de doses de glyphosate no controle de Brachiaria plantaginea.

O experimento foi conduzido no campo experimental da Embrapa Trigo, em Passo Fundo, RS $\left(28^{\circ} 15^{\prime} \mathrm{S}, 52^{\circ} 24^{\prime} \mathrm{W}\right.$ e $687 \mathrm{~m}$ de altitude), em Latossolo Vermelho distrófico típico, com 41,0\% de argila e 4,2\% de matéria orgânica. Os fatores em estudo foram doses de glyphosate $(0,90,180$ e 360 gramas de equivalente ácido por hectare), orvalho (presença e ausência) e volume de calda de aplicação (100 e 200 litros por hectare).

O delineamento experimental foi o experimento em faixas, com quatro repetições. As parcelas mediram 3,5 x 5,0 m. A infestação de plantas daninhas era natural e constituída por Brachiaria plantaginea, cobrindo 100\% da parcela. Os tratamentos foram aplicados usando-se pulverizador costal de pressão constante, dada por gás carbônico, equipado com bicos Teejet 110 015. A pressão usada foi 
de $20 \mathrm{lb} \mathrm{pol}^{-2}$, com velocidade de trabalho ajustada para dar os volumes de calda a serem testados. Os tratamentos foram aplicados em $31 / 01 / 03$, das 7 h30 às 8 h30. Durante a aplicação dos tratamentos a temperatura do ar era de $19{ }^{\circ} \mathrm{C}$, a umidade relativa do ar, de $87 \%$, e a quantidade de orvalho, de $0,443 \mathrm{~mm} \cdot \mathrm{m}^{-2}$. Essa quantidade foi determinada pela diferença entre o peso de plantas de B. plantaginea úmidas e após secas ao ar ventilado, coletadas em quatro amostras de $50 \times 50 \mathrm{~cm}$ cada. Na faixa cujo tratamento seria sem orvalho, este foi retirado através de várias passadas de uma corda de náilon. As avaliações dos tratamentos foram feitas pela porcentagem de controle da espécie, aos 10 e 20 dias após a aplicação do tratamento (DAT), em relação à testemunha

A eficiência dos tratamentos no controle (dessecação) de B. plantaginea foi determinada aos 10 e 20 dias após o tratamento (DAT) pelo método de avaliação visual, atribuindo-se notas em porcentagem de controle em relação à testemunha. A escala empregada variou entre 0 (sem danos visíveis) e 100\% (dessecação total de plantas). Os dados de eficiência dos tratamentos foram submetidos à análise de variância. Na comparação das médias dos efeitos principais usou-se o teste F, empregando-se o programa SAS (proc glm), através da utilização de alguns contrastes de interesse, a fim de responder questões específicas, de interesse do estudo (Kuehl, 1994).

\section{RESULTADOS E DISCUSSÃO}

A eficiência de glyphosate no controle de B. plantaginea foi influenciada tanto pela dose como pelo volume de calda de aplicação, pela presença ou ausência de orvalho. Todas as interações (dose $\mathrm{x}$ orvalho, dose $\mathrm{x}$ volume, orvalho $\mathrm{x}$ volume e dose $\mathrm{x}$ orvalho $\mathrm{x}$ volume) foram significativas.

O efeito de doses foi significativo e os controles médios da espécie foram de 33,1 , 62,4 e 93,7\%, nas respectivas doses de 90, 180 e $360 \mathrm{~g}$ de equivalente ácido por hectare (Tabela 1). Os sintomas de intoxicação caracterizaram-se por amarelecimento seguido de necrose da parte aérea, típicos de produtos cujo mecanismo de ação ocorre na inibição da síntese de aminoácidos e cuja intensidade varia em função da dose do produto que é absorvido pela planta. Nas doses maiores, o aparecimento de sintomas foi mais rápido e mais intenso, com necrose de tecidos, enquanto na dose mais baixa (90 g) foram observados amarelecimento e diminuição da estatura de plantas.

O volume de aplicação (água) influenciou a eficiência de glyphosate. O controle da espécie daninha diminuiu com o aumento do volume. Por exemplo, o controle médio de B. plantaginea foi de $66,2 \%$ com 100 litros de calda por hectare, enquanto esse controle

Tabela 1 - Significância estatística dos contrastes das médias

\begin{tabular}{|c|c|c|}
\hline Contraste & Média & Significância pelo teste $\mathrm{F}$ \\
\hline $\begin{array}{l}\text { Efeito do orvalho } \\
\text { sem orvalho x com orvalho }\end{array}$ & $75,2 \times 50,4$ & $<0,0001$ \\
\hline $\begin{array}{l}\text { Efeito do orvalho e do volume de calda } \\
100 \mathrm{~L} \text { com orvalho x } 100 \mathrm{~L} \text { sem orvalho } \\
200 \mathrm{~L} \text { com orvalho x } 200 \mathrm{~L} \text { sem orvalho }\end{array}$ & $\begin{array}{l}55,0 \times 77,5 \\
45,8 \times 74,2\end{array}$ & $\begin{array}{l}<0,0001 \\
<0,0001\end{array}$ \\
\hline $\begin{array}{l}\text { Efeito de doses } \\
90 \mathrm{~g} \times 180 \mathrm{~g} \\
180 \mathrm{~g} \mathrm{x} 360 \mathrm{~g} \\
\end{array}$ & $\begin{array}{l}33,1 \times 62,4 \\
62,4 \times 93,7\end{array}$ & $\begin{array}{l}<0,0001 \\
<0,0001\end{array}$ \\
\hline $\begin{array}{l}\text { Efeito do volume de calda } \\
100 \mathrm{~L} \text { x } 200 \mathrm{~L}\end{array}$ & $66,2 \times 60,0$ & 0,0003 \\
\hline $\begin{array}{l}\text { Efeito do orvalho e da dose } \\
90 \mathrm{~g} \text { com orvalho } \mathrm{x} 90 \mathrm{~g} \text { sem orvalho } \\
180 \mathrm{~g} \text { com orvalho } \mathrm{x} 180 \mathrm{~g} \text { sem orvalho } \\
360 \mathrm{~g} \text { com orvalho } \times 360 \mathrm{~g} \text { sem orvalho }\end{array}$ & $\begin{array}{l}21,2 \times 45,0 \\
41,8 \times 83,1 \\
88,1 \times 99,3\end{array}$ & $\begin{array}{l}<0,0001 \\
<0,0001 \\
<0,0010\end{array}$ \\
\hline
\end{tabular}


baixou para $60 \%$ quando o volume foi aumentado para 200 litros de calda por hectare (Tabela 1), concordando com os resultados obtidos por Yerkes \& Weller (1996), que constataram melhor controle de Convolvulus arvensis com volumes de calda relativamente reduzidos do que quando usando volumes maiores. Esses melhores controles provavelmente se devem à maior concentração de ingrediente ativo na calda e, por conseqüência, na gota pulverizada (Ambach \& Ashford, 1982; Jordan, 1981).

A eficiência de glyphosate foi reduzida quando aplicado na presença de orvalho, em todas as doses do herbicida (Tabela 1). O controle médio da espécie na ausência de orvalho foi de $75,8 \%$, enquanto na presença o controle médio foi de 50,4\%. O efeito negativo dessa variável de ambiente na eficiência de glyphosate foi mais pronunciado nas doses menores do produto (90 e $180 \mathrm{~g}$ de equivalente ácido) que na dose maior testada (360 g de eq. ácido), o que pode ser atribuído à diluição e ao escorrimento do produto pela água presente sobre a folhagem (Jordan, 1981), principalmente quando se usou a maior quantidade de calda. A redução do volume de calda tem sido relatada por outros autores (McKinley et al., 1974; Richard Jr., 1991) como tendo efeito positivo, possibilitando a redução de doses de herbicidas e, assim, os impactos desses produtos. No entanto, as características da superfície das folhas, de espécies diferentes, podem alterar a retenção da calda e o escorrimento do herbicida. Em Digitaria sanguinalis, por exemplo, a presença de grandes quantidades de pêlos nas folhas e nos colmos pode favorecer a retenção de maiores quantidades de calda herbicida e, dessa forma, reduzir as perdas por escorrimento (Smeda \& Putnam, 1989).

Embora a temperatura e a umidade relativa sejam variáveis importantes para a eficiência de herbicidas, a presença de água sobre a folha, na forma de orvalho, reduziu o controle da espécie, provavelmente devido à diluição e ao escorrimento do produto das folhas, efeitos que foram mais evidentes para as doses mais baixas, aplicadas com o maior volume de calda de pulverização. Assim, houve efeito significativo da interação entre dose, volume e presença de orvalho. Sob condições adequadas ao crescimento de plantas daninhas e à aplicação de herbicidas, o controle de $B$. plantaginea com doses reduzidas de glyphosate pode ser maximizado pela redução do volume de calda e pela aplicação do produto na ausência de orvalho. Nessas condições, é possivel reduzir os custos de controle dessa espécie. A presença ou ausência de orvalho pode ser importante indicador na tomada de decisão sobre a aplicação do herbicida glyphosate.

\section{LITERATURA CITADA}

AMBACH, R. M.; ASHFORD, R. Effects of variation in drop makeup on the phytotoxicity of glyphosate. Weed Sci., v. 30, p. 221-224, 1982.

HAMMERTON, J. L. Environmental factors and susceptibility to herbicides. Weeds, v. 15, p. 330-336, 1967.

JORDAN, T. N. Effects of diluent volumes and surfactant on the phytotoxicity of glyphosate to bemudagrass (Cynodon dactilon). Weed Sci., v. 29, p. 79-83, 1981.

KUEHL, R. O. Treatment comparisons. In: KUEHL, R. O. Statistical principles of research design and analysis. Belmont: Duxbury Press, 1994. p. 66-107.

McKINLEY, K. S.; ASHFORD, R.; FORD, R. J. Effects of drop size, spray volume, and dosage on paraquat toxicity. Weed Sci., v. 22, p. 31-34, 1974.

RICHARD Jr. R. E. Optimizing diluent volume improves johnsongrass control in sugarcane (Saccharum sp.) with asulam. Weed Technol., v. 5, p. 363-368, 1991.

RITTER, R. L.; COBLE, H. D. Influence of temperature and relative humidity on the activity of acifluorfen. Weed Sci., v. 29, p. 480-485, 1981.

SMEDA, R. J.; PUTNAM, A. Effect of adjuvant concentration and carrier volume on large crabgrass (Digitaria sanguinalis) control with fluazifop. Weed Technol., v. 10, p. 105-109, 1989.

YERKES, C. D.; WELLER, S. C. Diluent volumes influence susceptibility of field bindweed (Convolvulues arvensis) biotypes to glyphosate. Weed Technol., v. 10, p. 565-569, 1996. 